\title{
APPLICATION OF NEW FERROCENE DERIVATIVE FOR ELECTROCATALYTIC DETERMINATION OF CAPTOPRIL USING MULTIWALL CARBON NANOTUBE MODIFIED CARBON PASTE ELECTRODE
}

\author{
Masumeh Taei*, Foroozan Hasanpour and Ghazaleh Zahedi \\ Chemistry Department, Payame Noor University,19395-4697 Tehran, Iran
}

(Received June 7, 2014; revised December 6. 2014)

\begin{abstract}
A carbon-paste electrode modified with the N-4,4'-azodianiline (ferrocenyl Schiff base) and with multiwall carbon nanotubes was used as a highly sensitive and fairly selective electrochemical sensor for trace level determination of captopril. This modified electrode shows very efficient electrocatalytic activity for anodic oxidation of captopril via substantially decreasing of anodic overpotential. The measurements carried out by application of electrochemical impedance spectroscopy, differential pulse voltammetry, cyclic voltammetry and chronoamperometry. It has been found that under optimum conditions, the oxidation of captopril occurs at potential less positive than the unmodified carbon paste electrode. The kinetic parameters such as electron transfer coefficient $(\alpha)$ and rate constant for chemical reaction between captopril and redox sites in the modified electrode were 0.31 and $1.82 \times 10^{2} \mathrm{~cm}^{3} \mathrm{~mol}^{-1} \mathrm{~s}^{-1}$, respectively. The catalytic peak current was linearly dependent on the captopril concentration in the range of $0.1-625.0 \mu \mathrm{mol} \mathrm{L}{ }^{-1}$ with a detection limit of $0.03 \mu \mathrm{mol} \mathrm{L}^{-1}$. Finally, the modified electrode was examined as a selective, simple, and a precise new electrochemical sensor for the determination of captopril in real sample, such as urine, with satisfactory results.
\end{abstract}

KEY WORDS: Captopril, N-4,4'-azodianilineferrocene, Modified carbon paste electrode, Multiwall carbon nanotubes

\section{INTRODUCTION}

Carbon paste electrodes (CPE) first reported by Adams [1] are widely applicable in both electrochemical and electroanalysis study offering low cost, favorable signal-to-background characteristics within the whole operational potential range, and, in particular, a wide variety in the way of how to effectively modify their surface, as well as the bulk [2-3]. A wide variety of modifiers including ferrocenes [4], polymers [5] and mercapto compounds [6] have been used with these versatile electrodes. Ferrocene and its derivatives are of increasing importance as regards biological applications [7]. Ferrocenyl compounds are already applied as electroactive labels of biologically active compounds because of chemical stability and non-toxicity [8]. Furthermore, incorporation of unique properties of nanoparticles with modified CPE produce major advances in the field of electrochemical sensors. Among nanoparticles, carbon nanotubes (CNTs) have extraordinary characteristics such as high electrical conductivities and high surface area with hollow geometry which make them suitable substrates for heterogeneous catalysis [9]. Captopril, 1-[(2S)-3-mercapto-2-methylpropionyl]-L-proline, an orally active inhibitor of the angiotensin-converting enzyme, has been widely used for the treatment of hypertensive diseases. Several electrochemical methods have been reported for the determination of captopril. The poor selectivity, slow kinetic of electrooxidation and very weak voltammetric responses of the target analyte at bare (unmodified) electrodes are often serious problems in detection with these electrodes. Various chemical modified electrodes using electron transfer mediators such as ferrocenes [10-11], catechol-derivative-multiwall carbon nanotubes [12], Mn-nanoparticles decorated organo-functionalized $\mathrm{SiO}_{2}-\mathrm{Al}_{2} \mathrm{O}_{3}$ mixed-oxide[13], and cobalt-5-nitrolsalophen [14] have been used for the electrocatalytic detection of captopril. Among modifiers, ferrocenes and its derivatives have broad applications as outer sphere redox mediators in solution because of being reversible, fast reacting, regenerated at low potential, $\mathrm{pH}$-independent and stability in both

*Corresponding author. E-mail: m.taei@ch.iut.ac.ir 
oxidized and reduced forms. The aim of this study is the synthesis of N-4,4'-azodianiline ferrocenyl (ADAF) and combination of chemical properties of ferrocene moieties with flexibility of $d$ - and $\pi$-orbitals of azo group. Furthermore, the present work intends to evaluate electrochemical behavior of carbon nanotube paste electrode modified azodianiline ferrocenyl in the presence of captopril and possible linear relationship of the electrochemical response with the concentration of captopril. Finally, in order to demonstrate the catalytic ability of the modified electrode in the electro-oxidation of captopril in real samples, this method was examined for the voltammetric determination of captopril in urine samples. Interestingly, no data have been reported so far on the application of electrocatalytic activity of azoferrocene molecules in sensors.

\section{EXPERIMENTAL}

\section{Apparatus}

All voltammetric measurements were carried out using an electrochemical system comprising the Metrohm Instrument (Herisau, Switzerland), Model 797 VA, and a conventional three electrode cell assembly $(\mathrm{Ag} / \mathrm{AgCl}$ electrode as reference electrode, a platinum wire as counter electrode and azodianiline ferrocenyl carbon nano tube paste electrode (ADAFCNTE) as working electrode). The $\mathrm{pH}$ of the solutions was controlled with a Corning $\mathrm{pH}$ meter (model 146). The electrode feature characterized by scanning electron microscopy (SEM) (Philips, XL30).

\section{Reagents}

All the chemicals were of analytical grade (Merck). Captopril was dissolved in distilled water to prepare $1 \times 10^{-3} \mathrm{~mol} \mathrm{~L}^{-1}$ as a stock solution. Other standard solutions were prepared by dilution of the stock solution with buffer. Phosphate buffer $\left(0.1 \mathrm{~mol} \mathrm{~L}^{-1}\right)$ solutions with different $\mathrm{pH}$ (38) values were used. Pure graphite powder (particle size $<50 \mu \mathrm{m})$ and MWCNTs $(8-15 \mathrm{~nm}$ diameter) was purchased from Iran's Research Institute of Petroleum Industry. High-viscosity paraffin $\left(\mathrm{d}=0.88 \mathrm{~kg} \mathrm{~L}^{-1}\right)$ was used for the preparation of the paste electrodes.

Synthesis of N-4,4'-azodianiline(ferrocenyl Schiff base)

N-4,4'-azodianiline(ferrocenyl Schiff base), was prepared in the following way: Ferrocene carbaldehyde (1 mmol, $0.214 \mathrm{~g})$ and 4,4'-azodianiline ( $1 \mathrm{mmol}, 0.212 \mathrm{~g})$ were added to a porcelain mortar and ground using a porcelain pestle at $50-60{ }^{\circ} \mathrm{C}$ for $3 \mathrm{~h}$. To the resulting red paste was added $20 \mathrm{~mL} \mathrm{n}$-hexane and ground by pestle for $10 \mathrm{~min}$. The obtained dark-red solid was filtered and air-dried. For further purification, the dark-red microcrystalline solid was recrystallized by slow evaporation of a 1:1 chloroform/n-hexane solution of the complex. After 2 days at room temperature, shiny red crystals of ADAF were formed in a yield of $75 \%$. Anal. calc. for $\mathrm{C}_{23} \mathrm{H}_{20} \mathrm{FeN}_{4}(\mathrm{MW}=408.268$ ): $\mathrm{C}, 67.66 ; \mathrm{H}, 4.94 ; \mathrm{N}, 13.73$. Found: $\mathrm{C}, 67.85 ; \mathrm{H}, 4.98$; $\mathrm{N}, 13.82 \%$. IR $\left(\mathrm{KBr}\right.$ pellet, $\left.\mathrm{cm}^{-1}\right): 1623(\mathrm{C}=\mathrm{N})$ and $1582(\mathrm{C}=\mathrm{C})$. UV-Vis $\left(\mathrm{CHCl}_{3}, \lambda_{\max } / \mathrm{nm}\right.$ $\left.\left(\varepsilon / \mathrm{M}^{-1} \mathrm{~cm}^{-1}\right)\right): 709$ (89), $513(80), 291$ (67450), 267 (41551), 195 (84017). ${ }^{1} \mathrm{H}$ NMR $\left(\mathrm{CDCl}_{3}\right)$ $\mathrm{CH}=\mathrm{N}(1 \mathrm{H}, \mathrm{s}, 8.37 \mathrm{ppm}), \mathrm{C}_{5} \mathrm{H}_{5}(5 \mathrm{H}, \mathrm{s}, 4.28 \mathrm{ppm}), \mathrm{C}_{5} \mathrm{H}_{4}(2 \mathrm{H}, \mathrm{t}, 4.90 \mathrm{ppm}$ and $2 \mathrm{H}, \mathrm{t}, 4.72 \mathrm{ppm})$.

\section{Preparation of the modified electrode}

The mixture of 0.07 MWCNTs, $0.01 \mathrm{~g}$ ADAF and $0.5 \mathrm{~g}$ graphite powder were mixed together. Then diethyl ether was added and mixture was mixed to get uniform mixture. After evaporation of diethyl ether, $0.3 \mathrm{~g}$ paraffin oil was added and the solids were mixed in the mortar and pestle to obtain a uniformly wetted paste. The prepared paste was inserted in to a glass tube (internal 
radius $2.2 \mathrm{~mm}$ ) with a copper wire placed into the glass tube for electrical connection. New surface was obtained after pushing an excess the paste and polishing it on a weighing paper. The multi-walled carbon nanotubes/carbon-paste electrode and azodianiline ferrocenyl paste electrode (ADAFPE) as an unmodified carbon paste electrode were prepared in the same way but without adding ADAF and carbon nanotubes, respectively.

\section{RESULTS AND DESCUSSION}

The FT-IR of synthesized ADAF is shown in Figure 1. As expected, it has a band in the region of $1623 \mathrm{~cm}^{-1}$ which can be attributed to the $v(\mathrm{C}=\mathrm{N})$ group. Furthermore, the characteristic band at $1582 \mathrm{~cm}^{-1}$ can be assigned to the $\mathrm{C}=\mathrm{C}$ group. Azo-containing compound system often exhibit stable radical intermediates for metal coordination. In synthesized ADAF, the flexibility of dand $\pi$-orbitals are combined to yield unique electrocatalytic property. Figure 2 shows SEM images of carbon paste electrode (CPE) (Figure 2a), ADAFPE (Figure 2b) and ADAFCNTE (Figure 2c). As can be seen, MWCNTs were dispersed in the carbon paste and filled pores between graphite particles. The ADAF on the surface of CNTs did not change CNTs' morphology, but only made it more compact. MWCNTs caused increasing active surface area of the electrode and electrooxidation current. Electrochemical impedance spectroscopy (EIS) used for measuring interface properties of the electrode and solution, including the electrode impedance, the capacity of the electric double layer and the surface electron transfer resistance $\left(\mathrm{R}_{\mathrm{ct}}\right)$. In the Nyquist diagram, the semicircle diameter of EIS is equal to $\mathrm{R}_{\mathrm{ct}}$. Figure 3 illustrates the Nyquist diagrams of CPE (curve a), CNTPE electrode (curve b), ADAF modified carbon paste electrode (ADAFPE)(curve c) and ADAFCNTE (curve d) in the presence of $1.0 \times 10^{-3} \mathrm{~mol}$ $\mathrm{L}^{-1}\left[\mathrm{Fe}(\mathrm{CN})_{6}\right]^{3-/ 4-}(1: 1)+0.1 \mathrm{~mol} \mathrm{~L}^{-1} \mathrm{KCl}$ in phosphate buffer solution (pH 7.0). It can be seen that at the CPE, a semicircle with $\mathrm{R}_{\mathrm{ct}}$ about $32.0 \mathrm{k} \Omega$ was obtained. However, the diameter of the high frequency semicircle was obviously reduced to $9.4 \mathrm{k} \Omega$ by modification of the CPE with MWCNTs (curve b), suggesting that a significant acceleration for $\left[\mathrm{Fe}(\mathrm{CN})_{6}\right]^{3-/ 4-}$ redox reaction occurred due to the presence of MWCNTs. Also, the $\mathrm{R}_{\mathrm{ct}}$ of ADAFPE and ADAFCNTE obtained was about 49.1 and $16 \mathrm{k} \Omega$, respectively. As expected, decrease of charge transfer resistance value for multiwalled carbon nanotube paste electrode is due to acting these MWCNTs as conductive shreds.

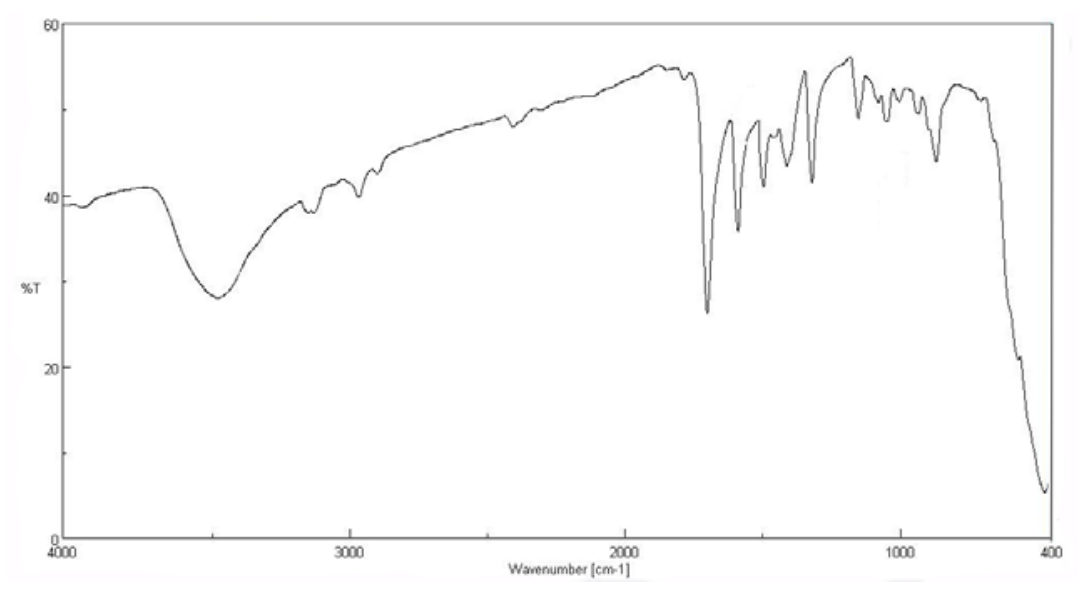

Figure 1. FT-IR of synthesized ADAF. 

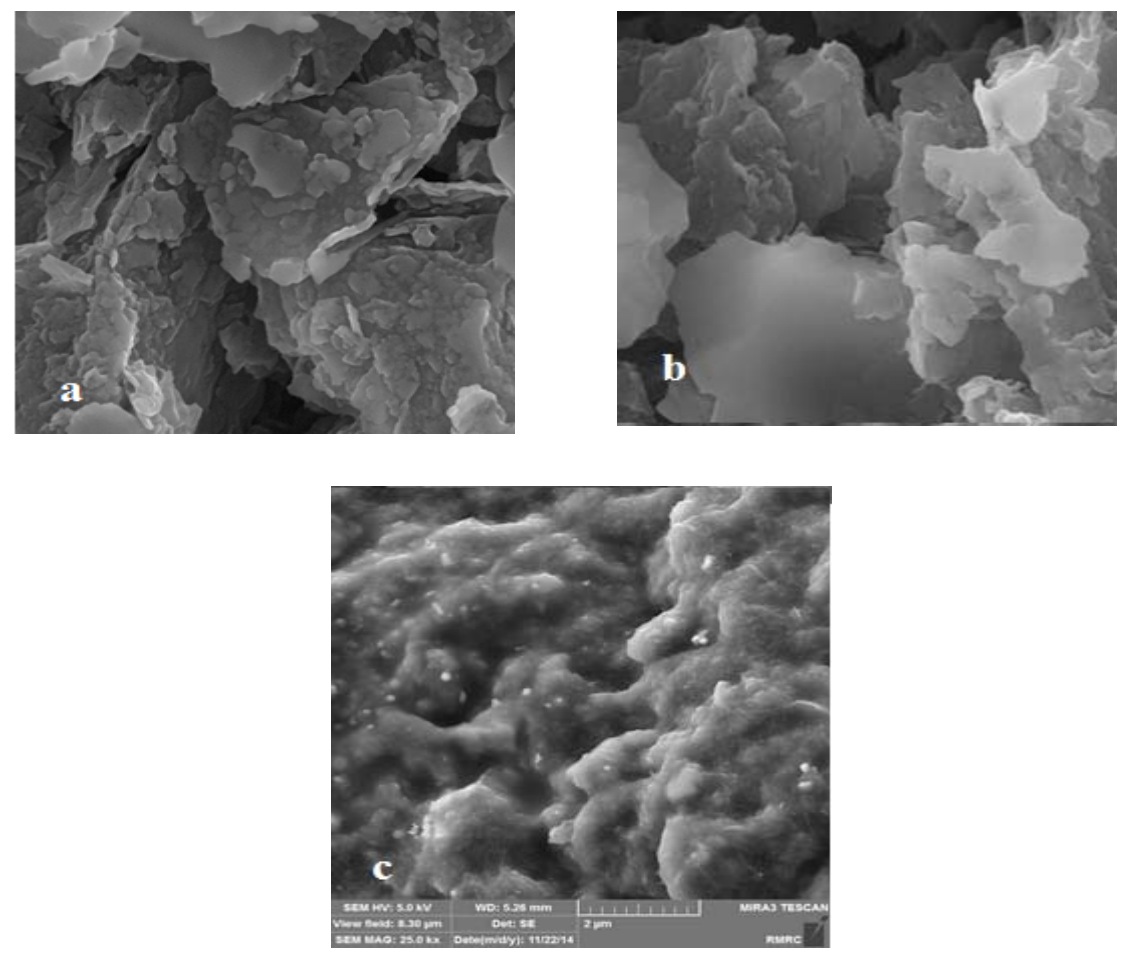

Figure 2. SEM image of a) CPE, b) ADAFPE and c) ADAFCNTE.

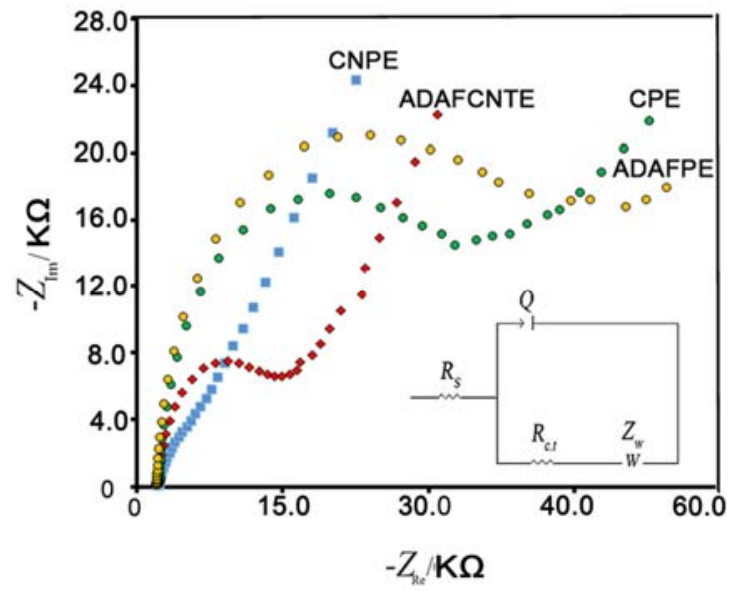

Figure 3. Nyquist diagrams of CPE (curve a), CNTPE electrode (curve b), ADAFPE (curve c) and ADAFCNTE (curve d) in the presence of $1.0 \times 10^{-3} \mathrm{~mol} \mathrm{~L}^{-1}\left[\mathrm{Fe}(\mathrm{CN})_{6}\right]^{3-/ 4-}(1: 1)+$ $0.1 \mathrm{~mol} \mathrm{~L}^{-1} \mathrm{KCl}$ in phosphate buffer solution $(\mathrm{pH} 7.0)$. 
It is well known that the electrochemical behavior of captopril is dependent on the $\mathrm{pH}$ value of the aqueous solution, whereas the electrochemical properties of N-4,4'-azodianiline (ferrocenyl Schiff base) is $\mathrm{pH}$ independent. Captopril has two dissociation constant that related to the carboxyl group $\left(\mathrm{pk}_{1}=3.7\right)$ and a thiol group $\left(\mathrm{pk}_{2}=9.8\right)$. In acidic solution, two peaks can be observed due to the oxidation of carboxylic and thiol group. The modified electrode shows the electrocatalytic activity for thiol group of captopril above $\mathrm{pH} 6$, however, the first oxidation peak decreased. Consideration of the application in biological system, $\mathrm{pH} 7.0$ was selected as the optimized value for further study. The electrochemical behavior of $400 \mu \mathrm{mol} \mathrm{L}{ }^{-1}$ of captopril solutions in phosphate buffer at different $\mathrm{pH}$ values was studied using the ADAFCNTE and differential pulse voltammetry. The results showed that maximum signal was obtained at $\mathrm{pH} 7.0$ (phosphate buffer).

The cyclic voltammogram (CV) of ADAFCNTE exhibited an anodic peak with $\mathrm{E}_{\mathrm{pa}}=0.54 \mathrm{~V}$ and cathodic peak with $\mathrm{E}_{\mathrm{pc}}=0.44 \mathrm{~V}$. The peak separation potential, $\Delta \mathrm{E}_{\mathrm{p}}=\left(\mathrm{E}_{\mathrm{pa}}-\mathrm{E}_{\mathrm{pc}}\right)=100.0 \mathrm{mV}$, was more than $59 / \mathrm{n} \mathrm{mV}$ excepted for a reversible system. This indicates that the redox couple in ADAF shows quasi-reversible in an aqueous medium. Also, the cyclic voltammetry results of this modified electrode in various buffered solutions do not show any shift in the anodic and cathodic peak potentials. Therefore, the electrochemical behavior of the redox process of $\mathrm{ADAF} / \mathrm{ADAF}^{+}$in $\mathrm{ADAFCNTE}$ is $\mathrm{pH}$-independent in aqueous solution.

The voltammetric behavior of ADAFCNTE in the buffer solution ( $\mathrm{pH} \mathrm{7.0)}$ is shown in Figure 4a. The CVs of CPE in captopril solution had no peak current in the range of 0.2 to $1.1 \mathrm{~V}$ (Figure $4 \mathrm{~b}$ ) in the absence of captopril CVs of ADAFCNTE had a well-defined electrooxidation peak current at $0.55 \mathrm{~V}$ (Figure 4c). In the presence of captopril in solution, the anodic peak current was increased, while the cathodic peak current was decreased (Figure 4d). This behavior is typical of that expected for an electrocatalytic reaction at the chemically modified electrodes [10-11]. Furthermore, the addition of MWCNTs to the modified electrode increases the peak current (Figure 4e).

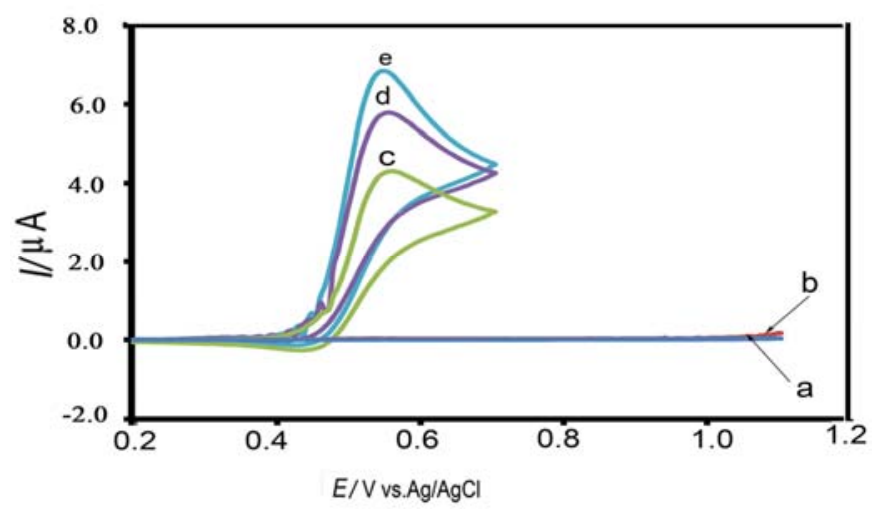

Figure 4. CVs of CPE in $0.05 \mathrm{~mol} \mathrm{~L}^{-1}$ phosphate buffer $(\mathrm{pH} 7.0)$ at a scan rate of $10 \mathrm{mV} \mathrm{s}^{-1}$ in the absence (a) and in the presence (b) of $400.0 \mu \mathrm{mol} \mathrm{L}^{-1}$ captopril, (c) As (a) and (d) as (b) for ADAFPE and (e) As (b) for ADAFCNTE.

Double potential step chronoamperometry was also employed to investigate the electrochemical behavior of the aqueous buffered solutions $(\mathrm{pH} 7.0)$ containing various concentrations of captopril $\left(0-500 \mu \mathrm{mol} \mathrm{L}{ }^{-1}\right)$ at ADAFCNTE by setting the working electrode potential at $0.40 \mathrm{~V}$ (at the first potential step) and $0.85 \mathrm{~V} v$ s. $\mathrm{Ag} / \mathrm{AgCl}$ (at the second potential step). A plot of I vs. $t^{-1 / 2}$ for ADAFCNTE in the presence of captopril gives a straight line and 
mean value of the diffusion coefficient was found to be $7.14 \times 10^{-5} \mathrm{~cm}^{2} \mathrm{~s}^{-1}$. The catalytic rate constant, $k_{\mathrm{h}},\left(\mathrm{cm}^{3} \mathrm{~mol}^{-1} \mathrm{~s}^{-1}\right)$ for the chemical reaction between captopril and the redox sites in ADAFCNTE, $k_{\mathrm{h}}$, can be evaluated by chronoamperometry according to the method described in [15-16]:

$$
\left(\mathrm{I}_{\mathrm{C}} / \mathrm{I}_{\mathrm{L}}\right)=\left(\pi \mathrm{K}_{\mathrm{h}} \mathrm{C}_{\mathrm{b}} \mathrm{t}\right)^{1 / 2}
$$

where, $I_{\mathrm{C}}$ is the catalytic current of ADAFCNTE in the presence of captopril, $I_{\mathrm{L}}$ is the limited current in the absence of captopril, $C_{\mathrm{b}}$ is the bulk concentration of captopril and $\mathrm{t}$ is time elapsed (s). From the slope of $I_{\mathrm{C}} / I_{\mathrm{L}}$ versus $t^{1 / 2}$ plot, the value of $k_{\mathrm{h}}$ can be simply calculated as $1.82 \times 10^{2} \mathrm{~cm}^{3} \mathrm{~mol}^{-1} \mathrm{~s}^{-1}$. To study the rate determining step, a Tafel plot was developed for ADAFCNTE using the data derived from the raising part of the current-voltage curve. The slope of the Tafel plot is equal to $2.3 \mathrm{RT} / \mathrm{n}(1-\alpha) \mathrm{F}$ or to $0.086 \mathrm{~V}$ decade ${ }^{-1}$. Using this data gives $\mathrm{n}(1-\alpha)=0.69$. If assuming $\mathrm{n}=1$, then $\alpha=0.31$. Calibration curve which obtained from differential pulse voltammetry, exhibited linear dynamic range of $0.1-625 \mu \mathrm{mol} \mathrm{L}^{-1}$ for captopril with the regression equation of $\mathrm{I}_{\mathrm{p}}(\mu \mathrm{A})=(0.0109 \pm 0.0010) \mathrm{C}_{\text {captopril }}+(23.52 \pm 0.90)\left(\mathrm{R}^{2}=09952\right)$, where $\mathrm{C}_{\text {captopril }}$ is concentration in $\mu \mathrm{mol} \mathrm{L} \mathrm{L}^{-1}$ (Figure 5). The detection limit (defined as $3 \mathrm{~s}_{\mathrm{b}} / \mathrm{m}$ where $s_{b}$ is the standard deviation of the blank signal $(n=10)$ and $m$ is the slope of the calibration curve) was found to be $0.03 \mu \mathrm{mol} \mathrm{L}^{-1}$.

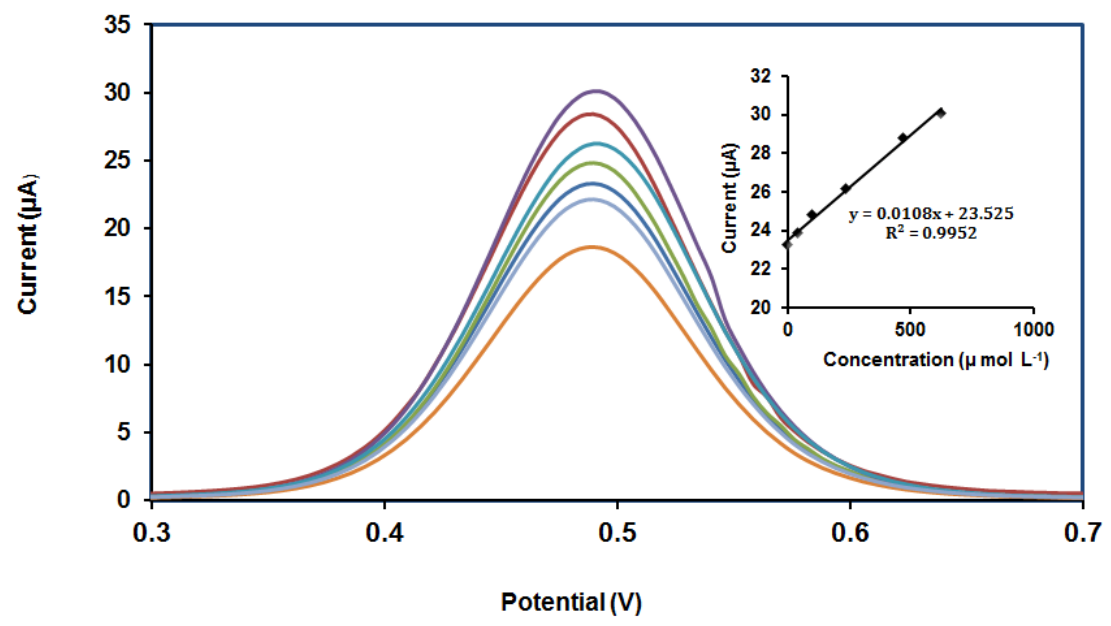

Figure 5. Differential pulse voltammograms of a) 0 , b) 0.1 , c) 40, d)100, e) 235, f) 470 and g) $625 \mu \mathrm{mol} \mathrm{L} \mathrm{L}^{-1}$ of captopril at ADAFCNTE in $0.05 \mathrm{~mol} \mathrm{~L}^{-1}$ phosphate buffer $(\mathrm{pH} 7.0)$ and scan rate of $20 \mathrm{mV} \mathrm{s}^{-1}$.

Stability, repeatability and reproducibility of adafcnte

The stability of the ADAFCNTE was checked out by DPV in $0.1 \mathrm{M}$ PBS (pH 7.0) and $4{ }^{\circ} \mathrm{C}$ containing $50.0 \mu \mathrm{mol} \mathrm{L}{ }^{-1}$ of captopril. The peak heights of the DPV were only decreased less than $6.1 \%$ of the initial oxidation peak current over a one-week period. In order to investigate the repeatability of the electrode the six repetitive measurements were carried out in $50.0 \mu \mathrm{mol}$ $\mathrm{L}^{-1}$ of captopril. The oxidation current was almost unchanged and RSD of $3.8 \%$ was observed. For five identical and independent modified electrodes, experimental results showed relative standard deviations of $4.6 \%$ towards the oxidation of $50 \mu \mathrm{mol} \mathrm{L} \mathrm{L}^{-1}$ captopril. 


\section{Interferences}

Effect of various potential interferences on the signal of captopril was studied under the optimum conditions with $50 \mu \mathrm{mol} \mathrm{L} \mathrm{L}^{-1}$ captopril. The tolerance limit was defined as the maximum concentration of the interfering substance that caused an error less than $\pm 5 \%$ for the determination of captopril. The results showed that only 50 fold of thiol compounds such as cysteine and glutathione that have similar structure affect on the signal of captopril. To evaluate the analytical applicability of the proposed sensor, determination of captopril was done in urine samples by the standard addition method without any pretreatment step. The accuracy of the proposed method compared with a sensitive kinetic spectrophotometric method [17]. The results (Table 1) clearly demonstrate and confirm the capability of the ADAFCNTE in the voltammetric determination of captopril with high selectivity, accuracy, and good reproducibility.

Table 1. Determination of captopril in urine samples.

\begin{tabular}{|c|c|c|c|}
\hline Sample & Captopril added $(\mu \mathrm{M})$ & Found by method $(\mu \mathrm{M})^{*}$ & Found by standard method $(\mu \mathrm{M})$ \\
\hline \multirow{2}{*}{ Urine $^{\mathrm{a}}$} & - & $10.8 \pm 1.3$ & $11.4 \pm 0.8$ \\
& 10.0 & $22.5 \pm 2.1$ & $21.6 \pm 1.2$ \\
\hline \multirow{2}{*}{ Urine $^{\mathrm{b}}$} & - & $11.2 \pm 2.4$ & $12.2 \pm 1.3$ \\
& 50.0 & $59.8 \pm 3.7$ & $62.4 \pm 4.0$ \\
\hline \multirow{2}{*}{ Urine $^{\mathrm{c}}$} & - & $22.4 \pm 3.1$ & $23.3 \pm 1.7$ \\
& 200.0 & $224.3 \pm 6.4$ & $222.7 \pm 3.7$ \\
\hline \multirow{2}{*}{ Urine $^{\mathrm{d}}$} & - & $18.4 \pm 4.0$ & $20.2 \pm 2.1$ \\
& 50.0 & $56.9 \pm 5.6$ & $60.8 \pm 5.5$ \\
\hline
\end{tabular}

a,bampling after $3.0 \mathrm{~h}$ of administration of captopril tablet from female heart patient and ${ }^{\mathrm{c}, \mathrm{d}}$ healthy volunteers. "Average of three replicated measurements. \pm Standard deviation.

\section{CONCLUSION}

New derivative of ferrocene was synthesized and used for modification of CPE. Electrochemical behavior of captopril on the modified electrode was studied. ADAF had excellent electrocatalytic effect on the oxidation of captopril. Electrochemical approaches were used for determination diffusion coefficient and transfer coefficient. The proposed method has good linear dynamic range and it was applied for determination of captopril in urine samples.

\section{REFERENCES}

1. Adams, R.N. Anal. Chem. 1958, 30, 1576.

2. Svancara, I.; Kalcher, K.; Walcarius, K.; Vytras, K. Electroanalysis with Carbon Paste Electrodes, CRC Press: Boca Raton; 2012.

3. Svancara, I.; Vytras, K.; Kalcher, K.; Walcarius, A.; Wang, J. Elactroanalysis 2009, 21, 7.

4. Khalilzadeh, M.A.; Karimi-Maleh, H.; Amiri, A. Chin. Chem. Lett. 2010, 21, 1467.

5. Antiochia1, R.; Tasca, F.; Mannina, L. Mater. Sci. Appl. 2013, 4, 15.

6. Mashhadizadeh, M.H.; Ramezani, S.; Ebrahimi, S. Sens. Actuator. B 2012, 169, 305.

7. Metzler-Nolte, N.; Salmain, M. in Ferrocenes: Ligands, Materials and Biomolecules, John Wiley and Sons: London; 2008.

8. Salmain, M. in Bioorganometallics, Wiley-VCH: Weinheim; 2006; p 181.

9. Ashrafi, A.M.; Cerovac, S.; Mudric, S.; Guzsvany, V.; Husakova, L.; Urbanova, I.; Vytras, K.; Sens. Actuator. B 2014, 191, 320.

10. Ensafi, A.A.; Monsef, M.; Rezaei, B.; Karimi-Maleh, H. Anal. Methods 2012, 4, 1332. 
11. Beitollahi, H.; Taher, M.A.; Ahmadipour, M.; Hosseinzadeh, R. Measurement 2014, 47, 770 .

12. Ensafi, A.A.; Karimi-Maleh, H.; Mallakpour, S. Colloids and Surfaces B: Biointerfaces 2011, 87,480 .

13. Ensafi, A.A.; Karimi-Maleh, H.; Ghiaci,M.; Arshadi, M. J. Mater. Chem. 2011, 21, 15022.

14. Shahrokhian, S.; Karimi,M.; Khajehsharifi, H. Sens. Actuator. B 2005, 109, 278.

15. Galus Z. Fundamentals of Electrochemical Analysis, 2nd ed., Ellis Horwood: Chichester; 1991.

16. Mazloum-Ardakani, M.; Beitollahi, H.; Ganjipour, B.; Naeimi, H.; Nejati, M. Bioelectrochemistry 2009, 1, 75.

17. Rahman, N.; Anwar, N.; Kashif, M.; Hoda, N. Acta Pharm. 2006, 56, 347. 